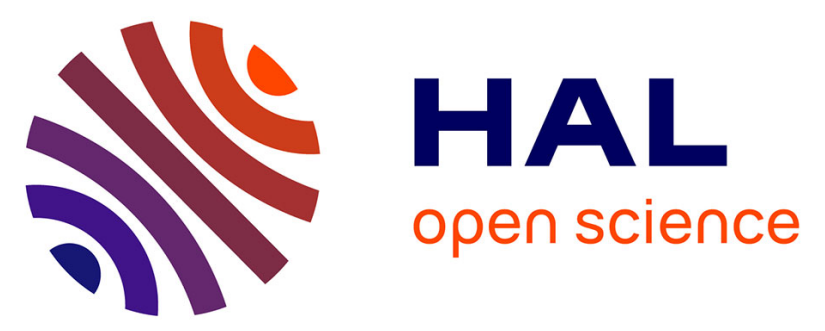

\title{
Cavitation in a hydraulic system: The influence of the distributor geometry on cavitation inception and study of the interactions between bubbles
}

\author{
Mahamadou Adama Maiga, Olivier Coutier-Delgosha, Daniel Buisine
}

\section{- To cite this version:}

Mahamadou Adama Maiga, Olivier Coutier-Delgosha, Daniel Buisine. Cavitation in a hydraulic system: The influence of the distributor geometry on cavitation inception and study of the interactions between bubbles. International Journal of Engine Research, 2015, june 2015, pp.1-13. $10.1177 / 1468087415590742$. hal-03169543

\section{HAL Id: hal-03169543 \\ https://hal.science/hal-03169543}

Submitted on 17 Jun 2021

HAL is a multi-disciplinary open access archive for the deposit and dissemination of scientific research documents, whether they are published or not. The documents may come from teaching and research institutions in France or abroad, or from public or private research centers.
L'archive ouverte pluridisciplinaire HAL, est destinée au dépôt et à la diffusion de documents scientifiques de niveau recherche, publiés ou non, émanant des établissements d'enseignement et de recherche français ou étrangers, des laboratoires publics ou privés. 


\title{
Cavitation in a hydraulic system: The influence of the distributor geometry on cavitation inception and study of the interactions between bubbles
}

\author{
Mahamadou Adama Maiga', Olivier Coutier-Delgosha' \\ and Daniel Buisine ${ }^{2}$
}

\begin{abstract}
Hydraulic systems are often subjected to pressure drops, which may lead to cavitation. In systems such as power steering, hoist loads, or ventricular assist devices, distributors are generally used. Significant pressure losses can happen in a distributor due to gap and overlap, which may lead to cavitation development. However, this issue is almost never included in the conception of the distributors. In this study, the multibubble model of the modified Rayleigh-Plesset equation is applied to the rotary distributor of an oil hydraulic system. The influence of the overlap length, the gap, the rotation speed, and distributor inlet pressure on the cavitation and particularly the interactions between bubbles at cavitation inception are studied. The study highlights a critical length of the overlap; over this value, the overlap length influences significantly the cavitation duration and the void fraction. More generally, some geometrical details have a strong influence on cavitation. Optimization of these details in engine parts, taking account the occurrence of cavitation, would be an appropriate solution to reduce its effects. The study also demonstrates that the growth of small bubbles may be delayed by the interactions with the nearby bigger ones, even if the ambient pressure is lower than their theoretical critical pressure. They eventually collapse at the first moments of the cavitation development. However, if the ambient pressure drops further, that is, beyond a critical pressure, a small bubble gains enough inertial energy to overcome these interaction phenomena and thus to grow. The growth of small bubbles increases the interactions between bubbles and slows down the growth of nearby bigger ones. The results show that the interactions between bubbles are of primary importance in the first moments of the cavitation development, which suggests that they should be taken into account in the definition of the critical pressure.
\end{abstract}

\section{Introduction}

Cavitation is the formation of the vapor phase in a liquid. It occurs when the liquid pressure drops to some critical value, which is mostly inevitable in hydraulic components such as pumps, marine propellers, inducers, and hydraulic turbines. This is particularly true in engines where the hydraulic systems are made of both fixed and rotating parts. Such assembly involves gaps (space left between two parts imperfectly assembled) and overlaps (the various flow passages are separated by spaces which avoids any leakage between the passages). Both these geometrical parameters and operation conditions (e.g. rotational speed) generate pressure drops, and thus appearance of cavitation, which is generally located on small areas and has a very short lifetime. So, cavitation in a hydraulic system is an interesting case for the study of cavitation inception.

\footnotetext{
'LML Laboratory (Laboratoire de Mécanique de Lille), Arts et Metiers ParisTech, Lille, France

${ }^{2}$ LML Laboratory (Laboratoire de Mécanique de Lille), Mechanic Department, Université des Sciences et technologies de Lille, Lille, France
}

Corresponding author:

Mahamadou Adama Maiga, LML Laboratory (Laboratoire de Mécanique de Lille), Arts et Metiers ParisTech, 8 bld Louis XIV, 59046 Lille, France. Email: Mahamadou.ADAMAMAIGA@ensam.eu 
Cavitation inception usually consists of a multitude of microscopic bubbles, whose behavior is especially complex. For example, in his experimental study of the cavitation inception, $\mathrm{Ohl}^{1}$ concludes that the bubblebubble interactions have to be taken into account for accurate modeling. Thus, the use of a simple singlebubble model is not appropriate. The further development of cavitation is often also difficult to handle, especially because of its unsteady behavior at various scales. In Barre et al., ${ }^{2}$ new special data processing methods were developed to estimate the void ratio and velocity fields in cold water flows. In this study, although the global behavior of the sheet cavities seems steady, experimental data exhibit a re-entrant jet which creates small cloud shedding. Moreover, cavitation is usually associated to damage (erosion, vibration, breaking, and so on), loss of performance, and sound emission. $^{3-10}$

It is very well known in the industry that the dimensions of the hydraulic engine parts can strongly influence the cavitation. A booster pump is generally used to counterbalance the pressure drops and thus reduce cavitation. In addition, existing works show that the optimization of the geometry of the parts can also reduce cavitation. In a study of the noise reduction of the oil pump TA96, Talha et al. ${ }^{11}$ show that noise and vibrations are maximum when the pump works in cavitating regime. The study concludes that a slight modification of the discharge chamber geometry, without altering the performance of the pump, leads to a significant decrease in the vibrations of the gear box, due to cavitation. An experimental and theoretical investigation has been conducted by Ruchonnet et al. ${ }^{12}$ on the influence of hydrodynamic cavitation in a limited section of a pipe on the eigenfrequencies of the hydroacoustic system. Study shows that a hydroacoustic mathematical model based on one-dimensional pipe flow was sufficient to describe this effect, with respect to the pipe length. Also, in a theoretical study of the cavitation problems in an axial piston pump, Wang ${ }^{13}$ has provided analytically the maximum overlap area required to fix the cavitation issues.

These different works confirm how crucial is the consideration of cavitation inception and development in the hydraulic systems of the engines. The objective of this work is to investigate the influence of overlap length, gap, rotational speed, and distributor inlet pressure on the inception and development of vapor bubbles in the rotating parts of a machinery and particularly to study the interactions between bubbles. The considered system is made of an oil tank, a booster pump, a rotary distributor, and a piston. The attention is particularly focused hereafter on the rotary distributor, which is used in most of the hydraulic systems (hoist loads, hydraulic shovels, power steering, ventricular assist device, etc.) to open and close the circulation channel by rotating action. In the considered system, it supplies the piston (simple acting cylinder) with pressurized oil.
For cavitation modeling, several works ${ }^{14-22}$ have been conducted. The models based on bubble dynamics $^{23,24}$ may be the most appropriate to take into account the microscopic structure of cavitation inception. Some single-bubble models have been extended in order to take into account the influence of the nearby bubbles. $^{25,26}$ So, for this study, a multibubble model is used.

This work is divided into two sections. The first section of this article is dedicated to the theoretical formulation, where the multibubble model and hydraulic system are presented, and to the evaluation of the pressure drops in the rotary distributor. The second section is dedicated to the results and discussions.

\section{Theoretical formulation}

\section{Multibubble model}

For the multibubble model, the modified RayleighPlesset equation ${ }^{27,28}$ is used. In this approach, the relative motion of bubbles is not taken into account. This assumption can be justified in the case where $D_{i j}$ the distance between the centers of bubbles $i$ and $j$ is much bigger than the initial radii of the bubbles $\left(D_{i j} \geqslant D_{0}\left(R_{0 i}+R_{0 j}\right)\right.$ with $\left.D_{0}=10^{28}\right)$. Indeed, Oguz and Prosperetti $^{29}$ and Doinikov ${ }^{30}$ have shown that in such case, the relative motion of the bubbles is very low. In addition, it is demonstrated in Bremond et al. ${ }^{27}$ that the modified Rayleigh-Plesset equation for two bubbles describes well the evolution of the bubble radii up to $75 \%$ of $D_{i j} / 2$. So, in this work, to fulfill these conditions, $D_{i j}$ is kept constant and $\left(R_{i}+R_{j}\right) \leqslant 0.75 D_{i j}$ with $R_{i}$ and $R_{j}$ the radii of bubbles $i$ and $j$, respectively.

With $N_{b}$ the number of bubbles, the modified Rayleigh-Plesset equation rewritten with respect to the flow rate is

$$
\begin{aligned}
\dot{q}_{i}= & \frac{1}{8 \pi} \frac{q_{i}^{2}}{R_{i}^{3}}-4 \frac{\mu_{L}}{\rho_{L}} \frac{q_{i}}{R_{i}^{2}}-\frac{8 \pi \sigma}{\rho_{L}} \\
& +\frac{4 \pi R_{i}}{\rho_{L}}\left(p_{g i}+p_{v}-p_{e x}(t)\right)-\sum_{j=1, j \neq i}^{N_{b}} \frac{R_{i}}{D_{i j}} \dot{q}_{j}
\end{aligned}
$$

with $q_{i}=4 \pi R_{i}^{2} \dot{R}_{i}$ is the flow rate across the interface of bubble $i, \dot{R}_{i}$ is the velocity normal to the interface, $\ddot{R}_{i} \quad$ is the interface acceleration, $\dot{q}_{i}=\partial q_{i} / \partial t=4 \pi\left(2 R_{i} \dot{R}_{i}^{2}+R_{i}^{2} \ddot{R}_{i}\right), \sigma$ is the surface tension, $\mu_{L}$ is the dynamic viscosity, $\rho_{L}$ is the density of the liquid, and $p_{i}$ is the pressure in the liquid at the bubble interface. The pressure inside the bubble equals the sum of the vapor pressure $p_{v}$ and the gas pressure $p_{g_{i}}$ modeled by the barotropic Laplace law

$$
p_{g_{i}}=\left(p_{0}+\frac{2 \sigma}{R_{0 i}}-p_{v}\right)\left(\frac{R_{0 i}}{R_{i}}\right)^{3 \gamma}
$$

$R_{0 i}$ is the initial radius, $\gamma$ is the polytropic exponent, $p_{0}$ is the atmospheric pressure, and $p_{e x}(t)$ is the ambient pressure. In the quasi-static approximation theory, a 


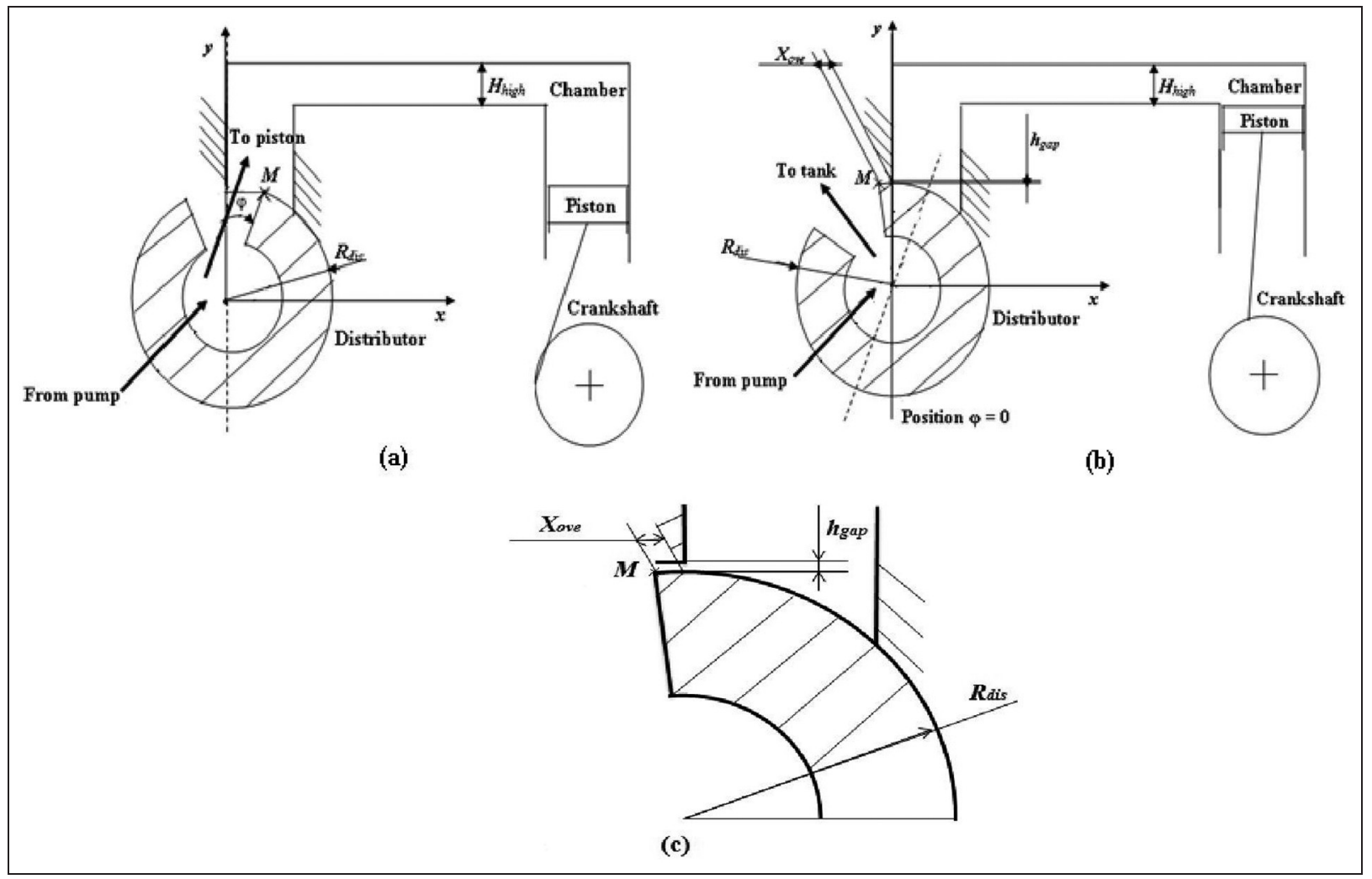

Figure I. Sketch of the system: (a) distributor opened, (b) distributor closed, and (c) zoom at the overlap in configuration (b).

first initial air bubble (called cavitation germ) $i$ starts to grow if the ambient pressure $p_{e x}(t)$ is lower than its critical pressure $p_{c s_{i}}$

$$
p_{c s_{i}}=p_{v}-\frac{4 \sigma}{3 R_{c s_{i}}}
$$

with the critical radius $R_{c s_{i}}$

$$
R_{c s_{i}}=R_{0 i} \sqrt{3\left(\frac{p_{0}-p_{v}}{2 \sigma} R_{0 i}+1\right)}
$$

It may be noted that the smaller is the bubble, the lower is the critical pressure.

\section{Hydraulic system and evaluation of pressure drop}

For this study, an oil hydraulic system is considered (Figure 1): it is composed of a tank, a pump, a rotating distributor, and a piston. A rotating distributor can be found, for example, in some cranes, hoist loads, excavators, and power steering hydraulic systems. When the distributor is opened, its function is to deliver the pressurized fluid coming from the pump toward the piston chamber (Figure 1(a)). When it is closed, the distributor is delivering the fluid to an oil tank (Figure 1(b) and (c)). In this system, pressure drops leading to cavitation inception are located in the chamber near the distributor. Cavitation occurs in the first moments of the distributor opening when the passage between the distributor and the chamber is narrow and consequently the pressure drop is high. The study in this article is focused on these conditions.

The pressure in the chamber is supposed to be uniform. It is calculated by the pressure drop in the passage between the distributor and the chamber. This allows having a simple configuration in which the flow rate is linked with the pressure drop.

When the distributor is closed, the flow can enter the chamber through $H_{\text {gap }}$ the gap between the distributor and the chamber casing: the pressure drop is then given by the Poiseuille equation. When the distributor is opened, the pressure drop is supposed to be singular and equal to the kinetic energy of the fluid coming from the distributor to the chamber.

The angle $\varphi=(\vec{y}, \overrightarrow{O M}$ ) (where $O$ is located at the distributor's axis and $M$ is at its periphery) determines the angular position of the distributor.

The abscissa $X_{\text {dis }}$ of $M$ (Figure 2) is

$$
X_{\text {dis }}=R_{\text {dis }} \sin \varphi-X_{\text {ove }}=R_{\text {dis }} \sin \omega t-X_{\text {ove }}
$$

where $R_{\text {dis }}$ is the radius of the distributor, $\omega=2 \pi \Omega / 60$ is its angular velocity, $\Omega$ is its rotational speed (in $\mathrm{r} /$ min) (which is assumed to be steady during the simulation), and $X_{\text {ove }}$ is the overlap length.

At the beginning of the simulation, the distributor is closed and $\varphi=0$ (Figure 2(b)), then $X_{\text {dis }}=-X_{\text {ove }}$. The distributor remains closed while $X_{\text {dis }}$ is negative.

We set $X_{c l o}$ the distributor travel for $X_{d i s}<0$ (when it is closed), while $X_{\text {ope }}$ is its travel when $X_{\text {dis }}>0$ (when it is opened) 


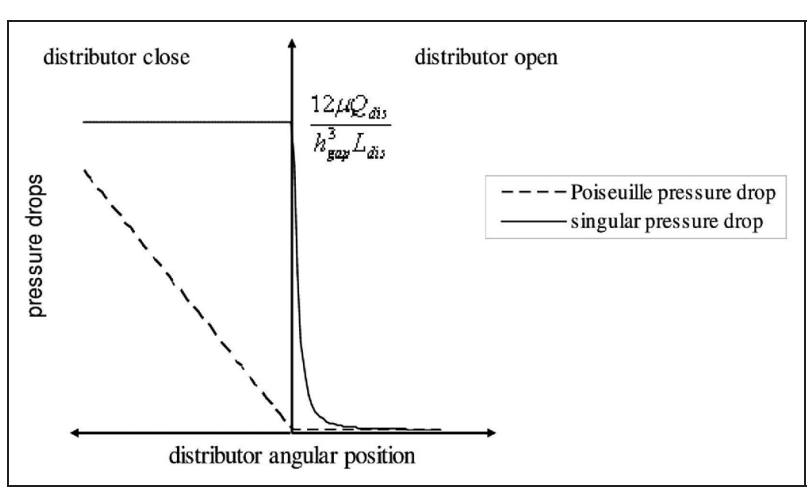

Figure 2. Evolution of the pressure drop as a function of the distributor angular position.

Solid line: singular pressure loss; dashed line: Poiseuille pressure loss.

$$
X_{c l o}=\frac{-X_{d i s}+\left|X_{d i s}\right|}{2} \text { is equal to }-X_{d i s}
$$

when $X_{d i s}<0$ and to 0 when $X_{d i s}>0$

$$
X_{\text {ope }}=\frac{X_{\text {dis }}+\left|X_{\text {dis }}\right|}{2} \text { is equal to } X_{\text {dis }}
$$$$
\text { when } X_{\text {dis }}>0 \text { and to } 0 \text { when } X_{\text {dis }}<0
$$

To simplify the study, when the distributor is closed, an overlap length of a few millimeters only is considered. In this case, the arc length is approximated to $X_{c l o}$ and the pressure drop is given by the Poiseuille formula

$$
\frac{X_{c l o}}{L_{d i s}} Q_{d i s}=\frac{h_{g a p}^{3}}{12} \frac{\delta p_{c l o}}{\mu_{L}}
$$

where $Q_{d i s}$ is the distributor flow rate, $L_{d i s}$ is the distributor width ( $z$ direction), $H_{\text {gap }}$ the gap between the distributor and chamber casing $\mu_{L}$ is the dynamic viscosity, and $\delta p_{c l o}=p_{\text {pump }}-p_{c}$ is the pressure loss inside the distributor, i.e. the pressure difference between the pump outlet and the chamber, if the pressure losses upstream and downstream the distributor are neglected.

When the distributor is opened, the singular pressure drop is

$$
\delta p_{\text {ope }}=\frac{\rho_{L}}{2}\left(\frac{Q_{\text {dis }}}{L_{\text {dis }} \sqrt{h_{\text {gap }}^{2}+X_{o p e}^{2}}}\right)^{2}
$$

with $\delta p_{\text {ope }}=p_{\text {pump }}-p_{c}$. In equation (9), the flow coefficient $C_{d}$ is assumed to be equal to 1 . Indeed, if the distributor is fully opened, $C_{d}$ is almost equal to 1 . During the opening phase, $C_{d}$ varies and is lower than 1 . Thus, assuming $C_{d}=1$ and constant enables to simplify the approach and also to make sure that the pressure drop is not underestimated.

The total pressure drop $\delta p$ is equal to

$$
\delta p=\delta p_{\text {clo }}+\delta p_{\text {ope }}
$$

The evolution of the pressure drop as a function of the distributor angular position is displayed in Figure 2, for $Q_{\text {dis }}$ constant. When the distributor is closed, the singular pressure drop is constant and equal to $0.5\left(Q_{d i s} / L_{d i s}\right)^{2}\left(\rho_{L} / h_{\text {gap }}^{2}\right)$, while the Poiseuille one is linear with a slope $\left(12 \mu_{L} Q_{d i s}\right) /\left(h_{\text {gap }}^{3} L_{d i s}\right)$. When the distributor is opened, the singular pressure drop tends asymptotically to zero while the Poiseuille one is constant and equal to zero.

Equations (8), (9), and (10) give

$$
\frac{1}{2\left(h_{\text {gap }}^{2}+X_{\text {ope }}^{2}\right)}\left(\frac{Q_{\text {dis }}}{L_{d i s}}\right)^{2}+\frac{12 \mu_{L} X_{\text {clo }}}{\rho_{L} h_{\text {gap }}^{3}} \frac{Q_{\text {dis }}}{L_{\text {dis }}}-\frac{\delta p}{\rho_{L}}=0
$$

Equation (11) shows a correlation between the flow rate at the outlet of the distributor and the chamber pressure. The chamber volume $V_{c h}$ can be expressed as follows

$$
V_{c h}=S_{p i s}\left(H_{h e i}+R_{c r a}(1-\cos (\omega t))\right)
$$

The derivative of equation (12) gives the flow rate $Q_{p i s}$, which is the volume variation due to the motion of the piston

$$
Q_{p i s}=S_{p i s} R_{c r a} \omega \sin \omega t
$$

where $S_{p i s}$ is the piston section, $R_{\text {cra }}$ is the crank shaft radius, and $H_{h e i}$ is the chamber height.

The mass conservation equation in the chamber, taking into account the volume variation of the bubbles, can thus be written as

$$
\sum_{i=1}^{N_{b}} q_{i}+Q_{d i s}-Q_{p i s}=0
$$

where $q_{i}=4 \pi \dot{R}_{i i} R_{i}^{2}$ is the flow rate at the interface of bubble $i$.

Equations (1), (11), (13), and (14) are the governing equations of the systems investigated.

\section{Numerical method}

The modified Rayleigh-Plesset equation (1) can be solved by the Runge-Kutta fourth-order method. The flow rate $Q_{d i s}$ is obtained at each time step from the resolution of equation (11), as the root of the same sign as $\Delta \delta p$, that is, the variation of the pressure loss in the distributor between two time steps.

To solve equation (1), the pressure $p_{c}$ is considered constant during the time step $\Delta t$. Once equations (1) and (11) are solved, $p_{c}$ is updated with respect to the continuity equation (14). As the pressure delivered by the pump is constant, the variation of $p_{c}$ during $\Delta t$ is equal to the variation of the pressure drop

$$
p_{c}^{n+1}-p_{c}^{n}=\Delta p_{c}=-\Delta \delta p
$$


Table I. Physical properties of the oil and geometrical characteristics of the hydraulic system.

\begin{tabular}{llll}
\hline Density in $40^{\circ}$ & $876 \mathrm{~kg} / \mathrm{m}^{3}$ & Piston area & $6 \times 10^{-5} \mathrm{~m}^{2}$ \\
Kinematic viscosity in $40^{\circ}$ & $4.6 \times 10^{-5} \mathrm{~m}^{2} / \mathrm{s}$ & Crank shaft radius & $2.5 \times 10^{-2} \mathrm{~m}$ \\
Superficial tension in $40^{\circ}$ & $0.029 \mathrm{~N} / \mathrm{m}$ & Chamber height & $5 \times 10^{-3} \mathrm{~m}$ \\
Pressure of vapor & $2400 \mathrm{~Pa}$ & Crossing area length & $2 \times 10^{-2} \mathrm{~m}$ \\
Polytropic exponent $(\gamma)$ & 1.4 & Distributor radius & $8 \times 10^{-3} \mathrm{~m}$ \\
\hline
\end{tabular}

The flow rate $q_{i}$ at time step $n+1$ is then

$$
\begin{aligned}
& q_{i}^{n+1}=\left(\dot{q}_{i}^{n}-\frac{4 \pi}{\rho_{L}} \Delta p_{c} R_{i}\right) \Delta t+ \\
& q_{i}^{n}=\Delta t \dot{q}_{i}^{n}+q_{i}^{n}+\frac{4 \pi \Delta t}{\rho_{L}} \Delta \delta p R_{i}
\end{aligned}
$$

with respect to equation (11), the variation $\Delta \delta p$ leads to a variation of entering flow rate $\Delta Q_{\text {dis }}$

$$
\begin{aligned}
& \left(\frac{\left|Q_{\text {dis }}\right|}{\left(h_{\text {gap }}^{2}+X_{\text {ope }}^{2}\right) L_{\text {dis }}^{2}}+\frac{12 \mu_{L} X_{\text {clo }}}{\rho_{L} h_{\text {gap }}^{3} L_{\text {dis }}}\right) \Delta Q_{\text {dis }}-\frac{\Delta \delta p}{\rho_{L}} \\
& =A_{\Delta Q} \Delta Q_{\text {dis }}-\frac{\Delta \delta p}{\rho_{L}}=0
\end{aligned}
$$

with

$$
A_{\Delta Q}=\left(\frac{\left|Q_{\text {dis }}\right|}{\left(h_{\text {gap }}^{2}+X_{\text {ope }}^{2}\right) L_{\text {dis }}^{2}}+\frac{12 \mu_{L} X_{\text {clo }}}{\rho_{L} h_{\text {gap }}^{3} L_{d i s}}\right)
$$

The mass conservation equation (14) for the time step $n+1$ is

$$
\begin{aligned}
& \sum_{i=1}^{N_{b}} q_{i}^{n+1}+Q_{\text {dis }}^{n+1}-Q_{\text {pis }}^{n+1} \\
& =\sum_{i=1}^{N_{b}} q_{i}^{n+1}+Q_{\text {dis }}^{n}+\Delta Q_{\text {dis }}-Q_{\text {pis }}^{n+1}=0
\end{aligned}
$$

Combining equations (15)-(18), the equation giving the pressure $p_{c}$ at the time step $n+1$ is obtained

$$
p_{c}^{n+1}=p_{c}^{n}+\frac{\varpi}{A_{\Delta p}}\left[\sum_{i=1}^{N_{b}}\left(\Delta t \dot{q}_{i}^{n}+q_{i}^{n}\right)+Q_{d i s}^{n}-Q_{p i s}^{n+1}\right]
$$

with $A_{\Delta p}=\left(4 \pi \Delta t / \rho_{L} \sum_{i=1}^{N_{b}} R_{i}+1 / \rho_{L} A_{\Delta Q}\right)$ and $\varpi$ is a relaxation coefficient.

\section{Initial conditions}

Experimental measurements of cavitation nuclei concentration $^{31}$ show that very few cavitation nuclei smaller than $1 \mu \mathrm{m}$ are detected, so in this study, the initial radius of the smallest bubble is fixed to $R_{0 N_{b}}=1 \mu \mathrm{m}$. A clean oil is considered in this study, so it is also supposed that the biggest bubble present initially in the oil has a radius $R_{01}=10 \mu \mathrm{m}$. To avoid excessive numerical cost, a number of bubbles $N_{b}=10$ are chosen hereafter.
The radii of the eight bubbles in between are determined by a geometrical continuation of reason

$$
\left(\frac{R_{0 N_{b}}}{R_{01}}\right)^{\frac{1}{N_{b}-1}}: R_{0 i}=\left(\frac{R_{0 N_{b}}}{R_{01}}\right)^{\frac{1}{N_{b}-1}} R_{0 i-1}, \quad i \geqslant 2
$$

The distance between the centers $i$ and $j$ of two bubbles is $D_{i j}=D_{0}\left(R_{0 i}+R_{0 j}\right)$ with $D_{0}=2000$ as in Ida et al. ${ }^{26}$ to enhance interactions between bubbles. The initial velocity of the interface $\dot{R}_{0 i}$ of bubble $i$ equals zero.

For this application, the HYSPIN AWS 46 oil produced by BP group is chosen. This oil is used for the hydraulic systems exposed to high pressure (power transmission systems, hydraulic jacks, etc.). Table 1 shows the oil physical properties and the geometrical characteristics of the hydraulic system.

\section{Results and discussion}

First of all, the conditions of a distributor inlet pressure of 10 bar, gap of $12 \mu \mathrm{m}$, overlap length of $0.15 \mathrm{~mm}$, and rotational speed of $1000 \mathrm{r} / \mathrm{min}$ are considered. Figure 3(a) displays the time evolution of the bubbles radii and Figure 3(b) is a zoom on the first $80 \mu \mathrm{s}$ of cavitation inception. The results show that the four smallest bubbles (7-10) have not developed. It can be expected that the pressure level for these flow conditions and/or some interactions between bubbles are responsible for this, which will be investigated hereafter. Figure 4 represents the time evolution of the void fraction, which is equal to the ratio between the sum of the bubble volumes and the chamber one $V_{c h}$. The void fraction gives a global understanding of the evolution of the bubbles and an estimation of the cavitation development.

Figure 5 displays the time evolution of the pressure in the chamber with a zoom at the first moments of cavitation. The general evolution shows a low pressure during the first $125 \mu \mathrm{s}$, before the distributor opening makes a sudden decrease in the head losses and the pump outlet pressure is recovered in the chamber. In detail, the lowest pressure is obtained for $0<t<50$ $\mu \mathrm{s}$, which corresponds to the bubble nucleation phase: the initial bubbles are small and progressively grow because of the low pressure due to the maximum head loss in the distributor. Then, the pressure remains almost constant during $80 \mu \mathrm{s}$, which enables the further development of the bubbles. Between $t=125$ and $150 \mu \mathrm{s}$, the head losses rapidly vanish as the distributor opening increases, which causes a large increase in the 


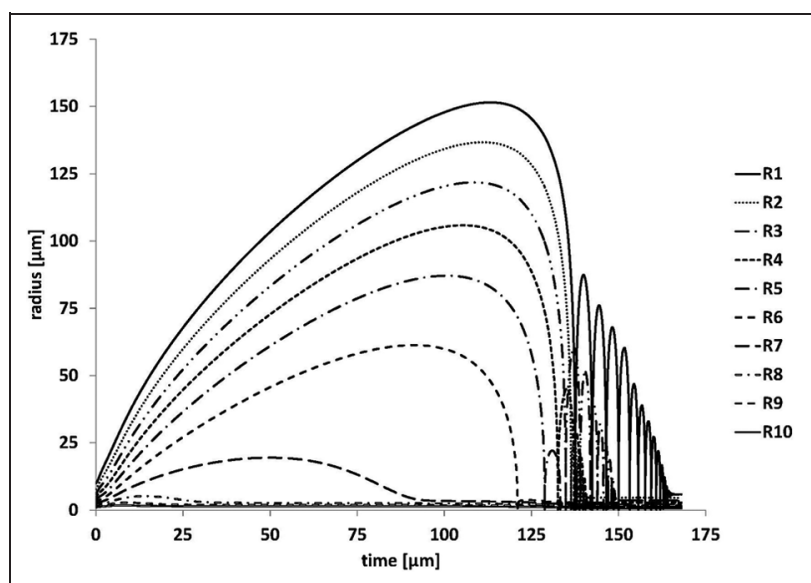

(a)

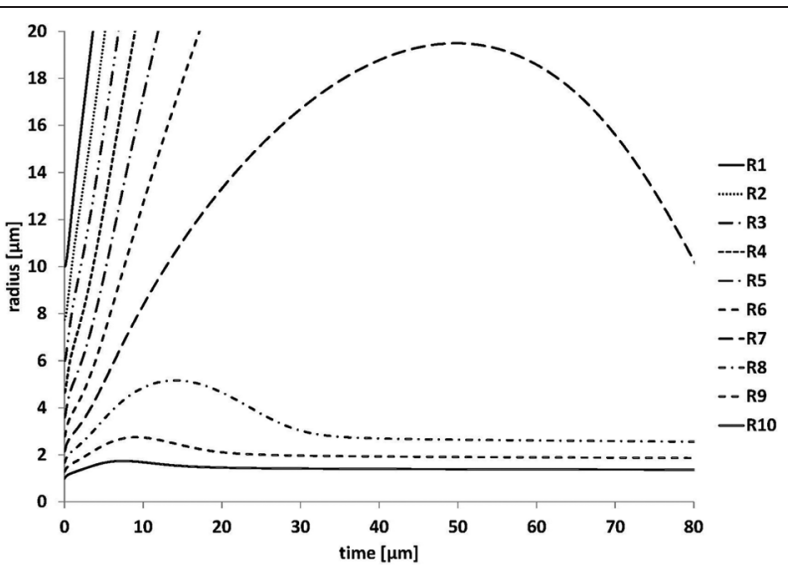

(b)

Figure 3. Time evolution of bubbles radii for (a) $X_{\text {ove }}=0.15 \mathrm{~mm}, H_{\text {gap }}=12 \mu \mathrm{m}, \Omega=1000 \mathrm{r} / \mathrm{min}$, and $p_{\text {pump }}=10$ bar; (b) $t<80 \mu \mathrm{s}$ $\left(X_{\text {ove }}=0.15 \mathrm{~mm}, H_{\text {gap }}=12 \mu \mathrm{m}, \Omega=1000 \mathrm{r} / \mathrm{min}\right.$, and $p_{\text {pump }}=10 \mathrm{bar}$ ).

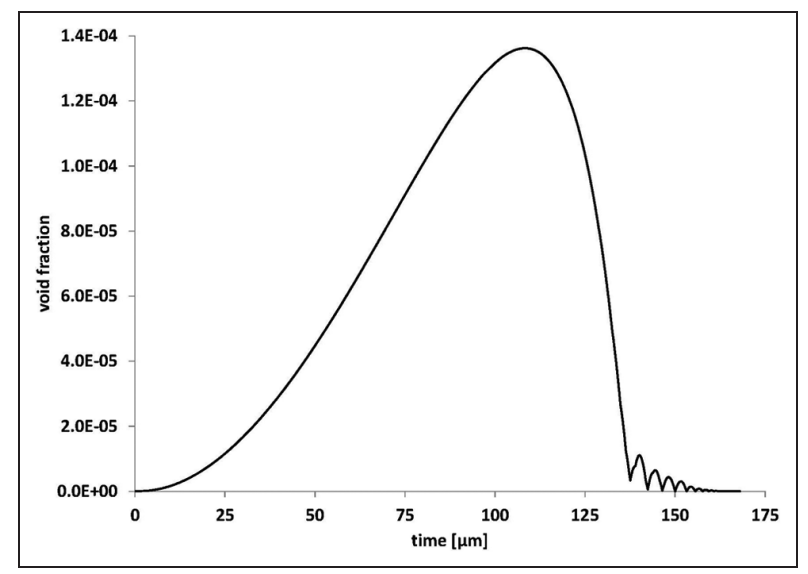

Figure 4. Time evolution of the void fraction for $X_{\text {ove }}=0.15 \mathrm{~mm}, H_{\text {gap }}=12 \mu \mathrm{m}, \Omega=1000 \mathrm{r} / \mathrm{min}$, and $p_{\text {pump }}=10$ bar.

pressure up to about 10 bar. During this stage, the bubbles collapse.

The following sections are devoted to the analysis of the effects of the overlap length, the gap, the rotational speed, and the distributor inlet pressure. Investigation will be focused on the evolutions of the biggest bubble and the void fraction (because it is representative of the biggest observable cavitation structures), the smallest one (to evaluate the effects of bubble interactions), and the pressure in the chamber. Parameters of interest will be especially the cavitation duration (time until the biggest bubble collapses and reaches its initial radius, without the rebound phase), the maximum radii of the bubbles and related void fraction, and the minimum pressure in the chamber.

\section{Influence of the overlap length}

The main role of the overlap is to reduce leaks and to maintain the pressure in the hydraulic system. Its length

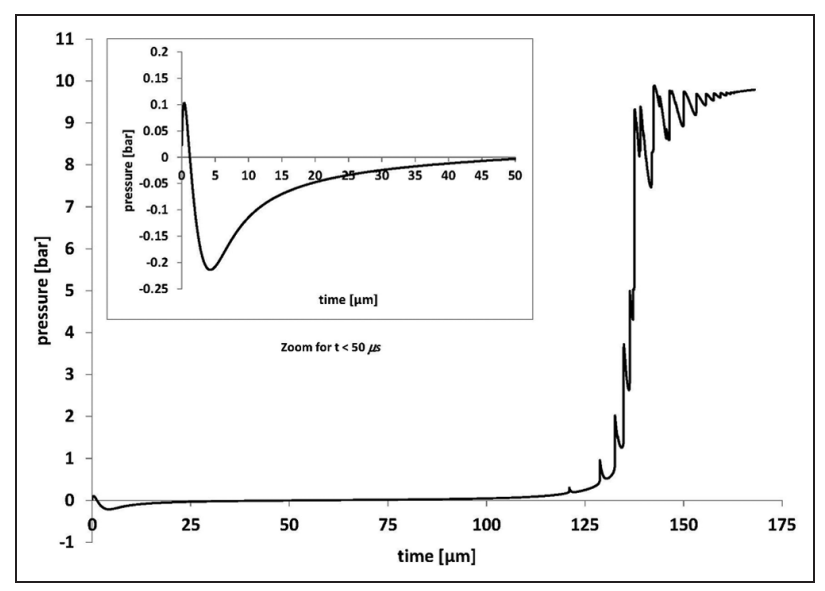

Figure 5. Time evolution of the pressure in the chamber for $X_{\text {ove }}=0.15 \mathrm{~mm}, H_{\text {gap }}=12 \mu \mathrm{m}, \Omega=1000 \mathrm{r} / \mathrm{min}$, and $p_{\text {pump }}=10 \mathrm{bar}$.

has to be minimized to avoid excessive distributor travel. Figure 6 shows that the cavitation duration is proportional to the overlap length, with a slope of $1673.6 \mu \mathrm{s} / \mathrm{mm}$. For $1 \mathrm{~mm}$ of the overlap length, the cavitation duration increases by $1.67 \mathrm{~ms}$, which can be compared, for example, to cavitation cycle durations in case of cavitating flows in a venturi or around hydrofoil, which are of the same order, ${ }^{32,33}$ so harmful effects may also be obtained in the present configuration. The linear trend curve shows that for an overlap length of $0.081 \mathrm{~mm}$, the cavitation duration equals 0 , as no bubble has sufficient time to develop. This overlap length can thus be considered the maximum appropriate overlap to avoid cavitation.

Figure 7 presents the minimum pressure in the chamber and the theoretical critical pressure of the smallest bubble as a function of the overlap length. It can be observed that for $X_{\text {ove }}<1.25 \mathrm{~mm}$, the minimum pressure varies with the overlap length, while remains constant over this critical value. 


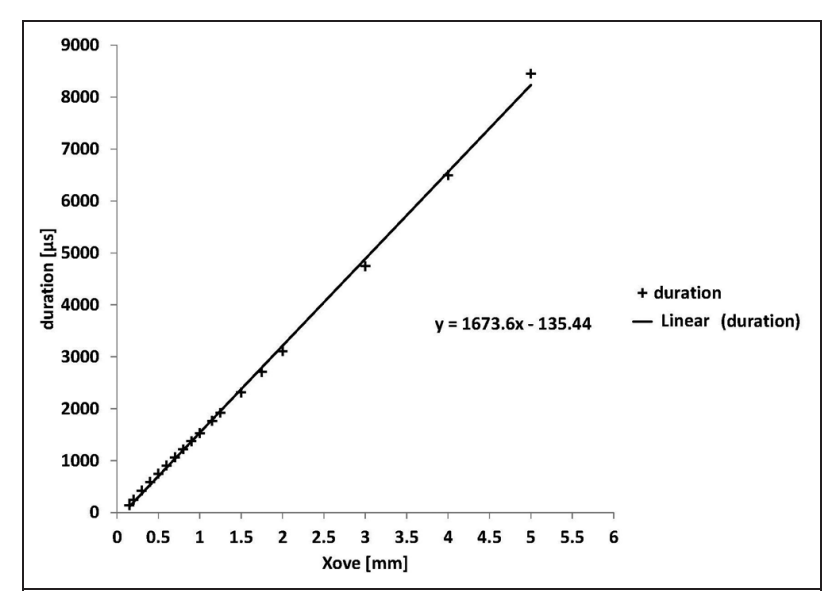

Figure 6. Cavitation duration with respect to the $X_{\text {ove }}$ for $H_{\text {gap }}=12 \mu \mathrm{m}, \Omega=900 \mathrm{r} / \mathrm{min}$, and $p_{\text {pump }}=10$ bar.

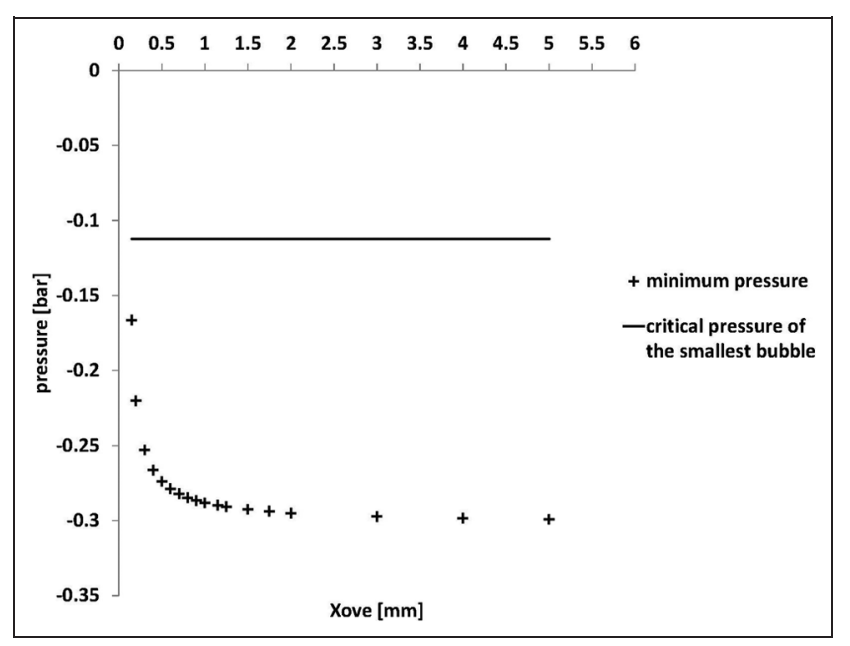

Figure 7. Variation of the minimum pressure in the chamber and the theoretical critical pressure of the smallest bubble with respect to the $X_{\text {ove }}$ for $H_{\text {gap }}=12 \mu \mathrm{m}, \Omega=900 \mathrm{r} / \mathrm{min}$, and $p_{\text {pump }}=10$ bar.

Figure 8 represents the maximum void fraction as a function of the overlap length. It confirms that $X_{\text {ove }}=1.25 \mathrm{~mm}$ is a critical value of the overlap: for $X_{\text {ove }}<1.25 \mathrm{~mm}$, the void fraction increases very slowly, while over this value, it varies linearly with a slope of $0.1284 \mathrm{~mm}^{-1}$. Accordingly, Figure 9 shows the same type of variation for the radius of the biggest bubble. With respect to this result, for $X_{\text {ove }}=1 \mathrm{~mm}$, the radius of the biggest bubbles is about $900 \mu \mathrm{m}$, approximately 3 times higher than those observed experimentally by Ohl. ${ }^{1}$ As the collapse of big bubbles is responsible for the shock waves that cause noise and damage, this result suggests that cavitation in the present configuration may be harmful.

Figures 10 and 11, which display the time evolutions $(t<80 \mu \mathrm{s})$ of the radii of all bubbles for $X_{\text {ove }}=0.15$ and $5 \mathrm{~mm}$, respectively, show in both cases that some of the smallest bubbles have not grown, so the void

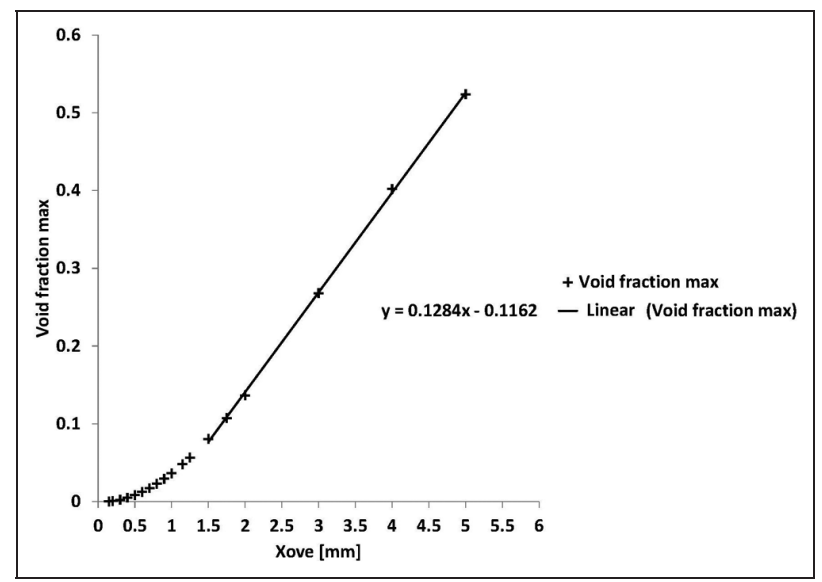

Figure 8. Maximum void fraction with respect to the $X_{\text {ove }}$ for $H_{\text {gap }}=12 \mu \mathrm{m}, \Omega=900 \mathrm{r} / \mathrm{min}$, and $p_{\text {pump }}=10 \mathrm{bar}$.

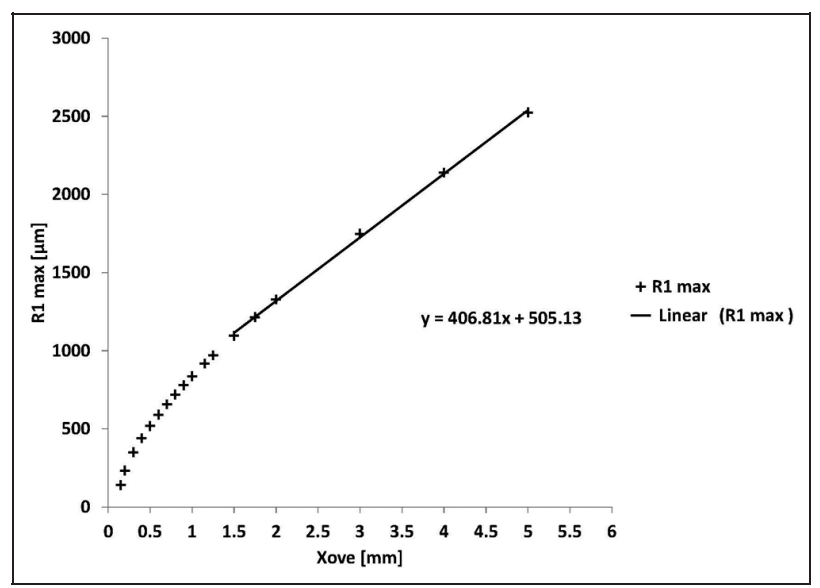

Figure 9. Maximum radius $R_{1}$ with respect to the $X_{\text {ove }}$ for $H_{\text {gap }}=12 \mu \mathrm{m}, \Omega=900 \mathrm{r} / \mathrm{min}$, and $p_{\text {pump }}=10 \mathrm{bar}$.

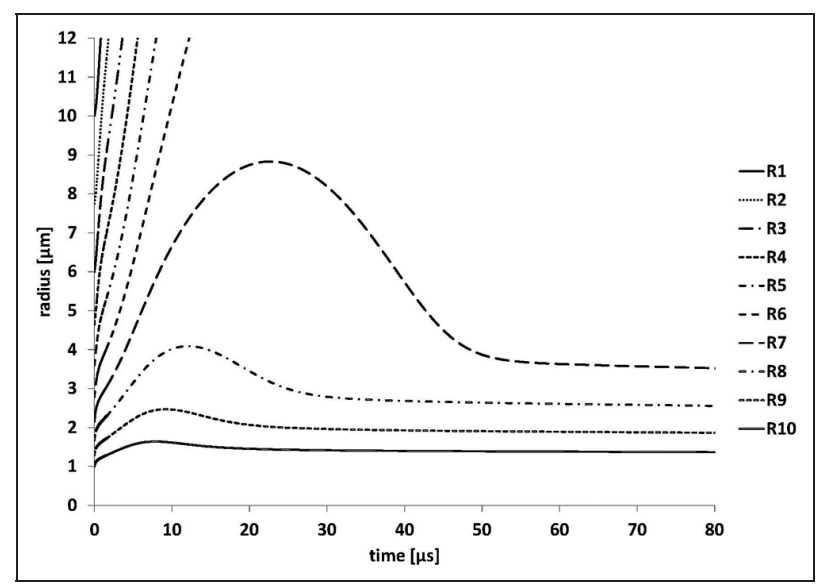

Figure 10. Time evolution of the bubble radii for $t<80 \mu \mathrm{s}$ $\left(X_{\text {ove }}=0.15 \mathrm{~mm}, H_{\text {gap }}=12 \mu \mathrm{m}, \Omega=900 \mathrm{r} / \mathrm{min}\right.$, and $p_{\text {pump }}=10$ bar $)$.

fraction results from the development of the six or seven biggest bubbles only. However, with respect to 


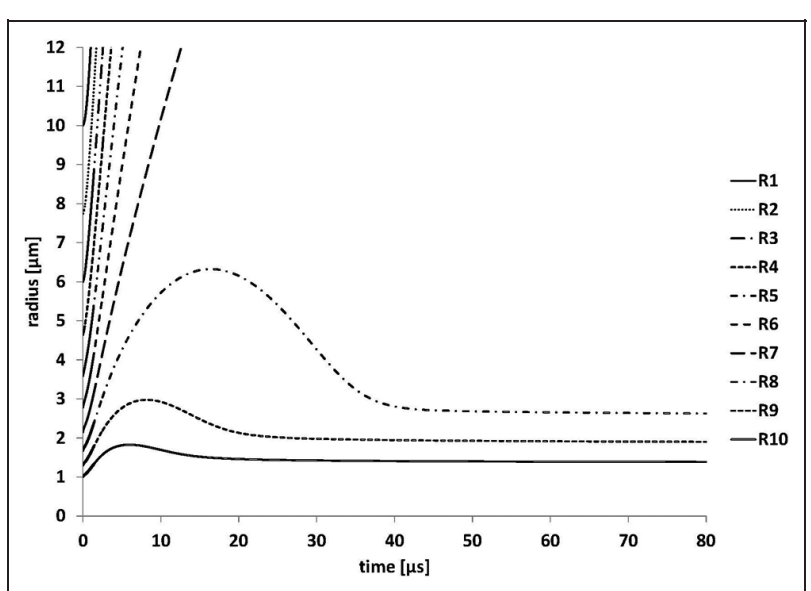

Figure II. Time evolution of the bubble radii for $t<80 \mu \mathrm{s}$ $\left(X_{\text {ove }}=5 \mathrm{~mm}, H_{\text {gap }}=12 \mu \mathrm{m}, \Omega=900 \mathrm{r} / \mathrm{min}\right.$, and $p_{\text {pump }}=10 \mathrm{bar}$ ).

Figure 7, all bubbles should grow, since the minimum pressure in the chamber is always lower than the critical pressure of the smallest bubble. So, the results suggest that the smallest bubbles, after they start to grow because of the initial pressure drop, are submitted to the interactions with the nearby biggest bubbles, which stops their development, and they eventually collapse in the early stage of the cavitation development.

These results show that the pressure drop, in practice, is not sufficient to allow these small bubbles to overcome the interactions with the nearby bigger ones and to develop. Conversely, the biggest bubbles, which will not be stopped by the interactions between bubbles at the first moments of cavitation, continue to grow during the long period where the pressure remains almost constant.

\section{Influence of the gap}

A gap is necessary between two rotating parts. It usually slightly increases in time; hence, it is useful to check its effects on cavitation development. In this study, the gap is varied between 0.01 and $0.03 \mathrm{~mm}$. These are typical values of assembly by hand and sliding fit, respectively. Figure 12 shows that the cavitation duration, the maximum void fraction, the maximum radius of the biggest bubble, the maximum radius of the smallest bubble, and the minimum pressure vary only slightly with respect to the gap.

\section{Influence of the rotational speed}

The fluid supply in hydraulic systems requires short response times, and thus high rotational speeds. It causes significant head losses in the distributor and eventually results in a low pressure in the chamber. Indeed, Figure 13 displays the minimum pressure and the theoretical critical pressure of the smallest bubble as a function of the rotational speed. It confirms that

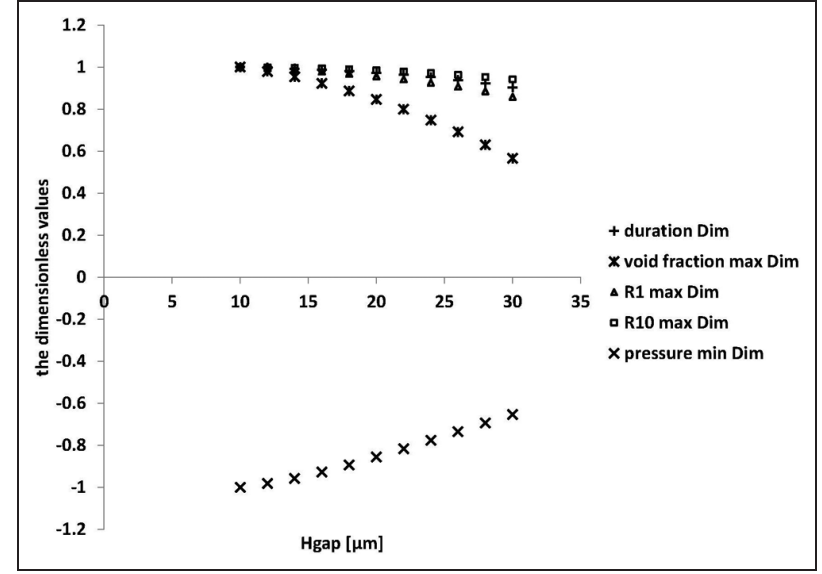

Figure 12. Dimensionless values of cavitation duration, maximum void fraction, maximum radius $R_{1}$, maximum radius $R_{10}$ and minimum pressure with respect to the $H_{\text {gap }}$ for $X_{\text {ove }}=\mathrm{I} \mathrm{mm}, \Omega=900 \mathrm{r} / \mathrm{min}$, and $p_{\text {pump }}=10$ bar (non-dimensional values obtained with reference values $1534.7084 \mu \mathrm{s}, 0.037$, $840.5822 \mu \mathrm{m}, \mathrm{I} .8262 \mu \mathrm{m}$, and 0.2934 bar, respectively).

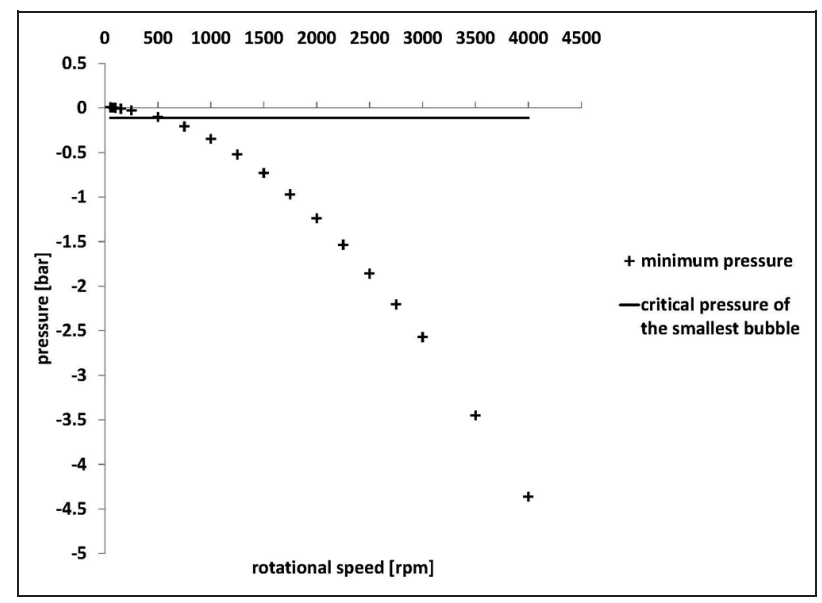

Figure 13. The minimum pressure and the theoretical critical pressure of the smallest bubble with respect to the $\Omega$ for $X_{\text {ove }}=1 \mathrm{~mm}, H_{\text {gap }}=12 \mu \mathrm{m}$, and $p_{\text {pump }}=10 \mathrm{bar}$.

the minimum pressure decreases when the rotational speed increases.

The increase in the pressure drop with the rotational speed $\Omega$ greatly influences the cavitation development, as can be seen in Figure 14, which displays the void fraction as a function of the rotational speed. Together with the increase in the void fraction, a similar increase in the cavitation duration is expected. However, Figure 15 , which represents the cavitation duration as a function of the rotational speed, shows that it decreases exponentially with $\Omega$, before remaining almost constant. This result shows that in case of high rotational speed, bigger bubbles are obtained, and their collapse is shorter. It suggests that violent collapses and associated harmful effects are expected in such operation conditions.

Figure 16 shows that the maximum radius of the biggest bubble is maximum for $\Omega$ close to $150 \mathrm{r} / \mathrm{min}$, 


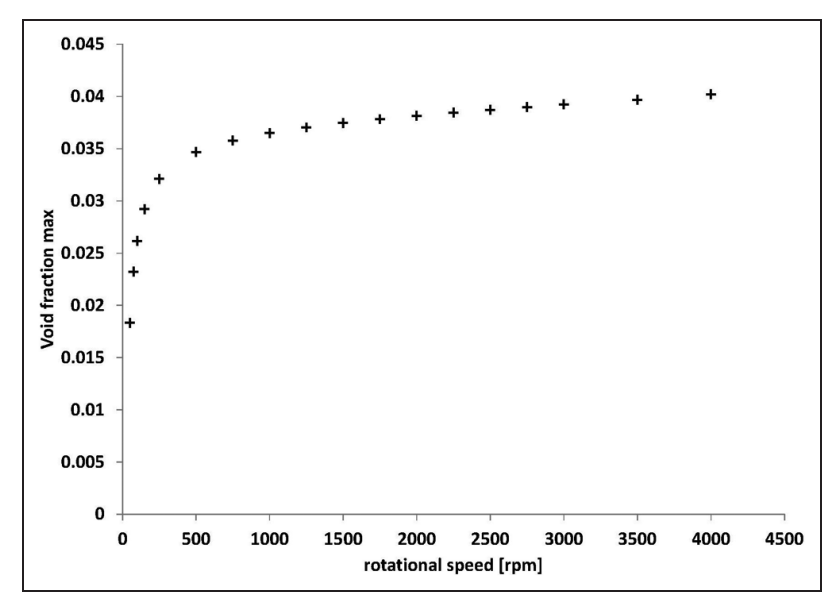

Figure 14. Maximum void fraction with respect to the $\Omega$ for $X_{\text {ove }}=1 \mathrm{~mm}, H_{\text {gap }}=12 \mu \mathrm{m}$, and $p_{\text {pump }}=10$ bar.

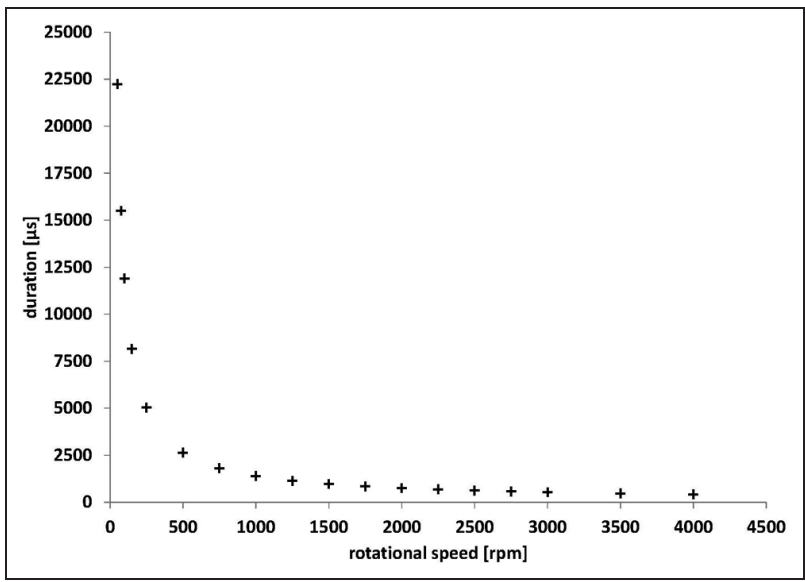

Figure 15. Cavitation duration with respect to the $\Omega$ for $X_{\text {ove }}=1 \mathrm{~mm}, H_{\text {gap }}=12 \mu \mathrm{m}$, and $p_{\text {pump }}=10 \mathrm{bar}$.

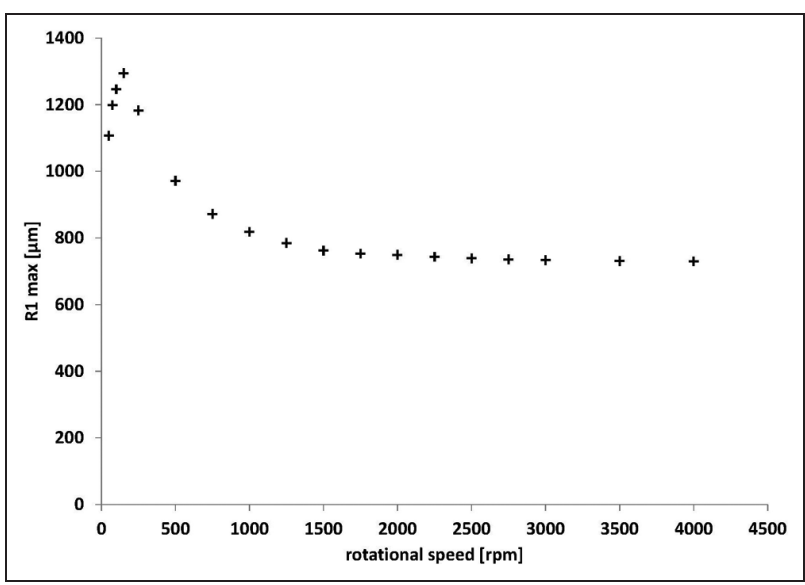

Figure 16. Maximum radius $R_{1}$ with respect to the $\Omega$ for $X_{\text {ove }}=1 \mathrm{~mm}, H_{\text {gap }}=12 \mu \mathrm{m}$, and $p_{\text {pump }}=10$ bar.

and then it reduces to a nearly constant value for higher rotational speeds. This decrease in $R_{1}$ seems inconsistent with the increase in the void fraction and also with the decrease in the minimum pressure which favors the growth of the bubbles. Figure 17(a) and (b), which displays the time evolution of the bubble radii for rotational speeds equal to 50 and $150 \mathrm{r} / \mathrm{min}$, respectively, indicates that only the biggest bubble develops, while no smaller bubble is obtained in its vicinity. Conversely, when $\Omega$ is increased up to $250 \mathrm{r} / \mathrm{min}$, one small bubble develops, as shown in Figure 17(c). So, the interaction between the bubbles for high rotational speed explains why the maximum radius of the biggest bubble decreases while the void fraction increases.

The more the rotational speed is increased, the more the minimum pressure decreases, and more small bubbles expand in the neighborhood of the biggest one. So, the increase in the rotational speed enhances the interaction phenomena between bubbles, which explains why the maximum radius of the biggest bubble is reduced. Above a certain value of the rotational speed, the minimum pressure is sufficiently small so that all the small bubbles close to the biggest one can grow, consequently the number of small bubbles interacting with the biggest one will remain almost constant (nine bubbles in that case) for higher rotational speeds, and the maximum radius of bubble 1 stabilizes as can be seen in Figure 16.

As shown in Figure 13, the minimum pressure becomes lower than the critical pressure of the smallest bubble around $500 \mathrm{r} / \mathrm{min}$. So, in theory, all bubbles should develop for $\Omega$ higher than $500 \mathrm{r} / \mathrm{min}$. However, it can be observed in Figure 18 that the smallest bubble does not grow if $\Omega$ is lower than $750 \mathrm{r} / \mathrm{min}$. This result is confirmed by Figure 19(a) and (b), which represents the time of evolution of the 10 bubbles for $\Omega=1750$ and $2000 \mathrm{r} / \mathrm{min}$, respectively. The results indicate that the critical pressures eventually predicted by the model are significantly lower than the theoretical critical pressures.

Figure 20 represents the theoretical and numerical critical pressures and the difference between them with respect to the initial radius of the bubble. It can be noticed that the difference is quite small for the big bubbles, while the smaller the bubble is, the more this difference increases. For the smallest bubble $(1 \mu \mathrm{m})$, the critical pressure difference is even close to 1 bar. This is likely due to the interactions between bubbles, which have more effects on the small bubbles than on the big ones.

\section{Influence of the distributor inlet pressure}

In this section, the effect of the pressure delivered by the pump, which equals the distributor inlet pressure (since the head losses upstream and downstream from the distributor are neglected in our approach) is investigated. As indicated in Figure 21, the minimum pressure varies smoothly with the pump outlet pressure with a very low slope of $2 \times 10^{-4}$. This modest variation was expected, as the pressure losses in the distributor are almost equal to the pump elevation in our approach. 


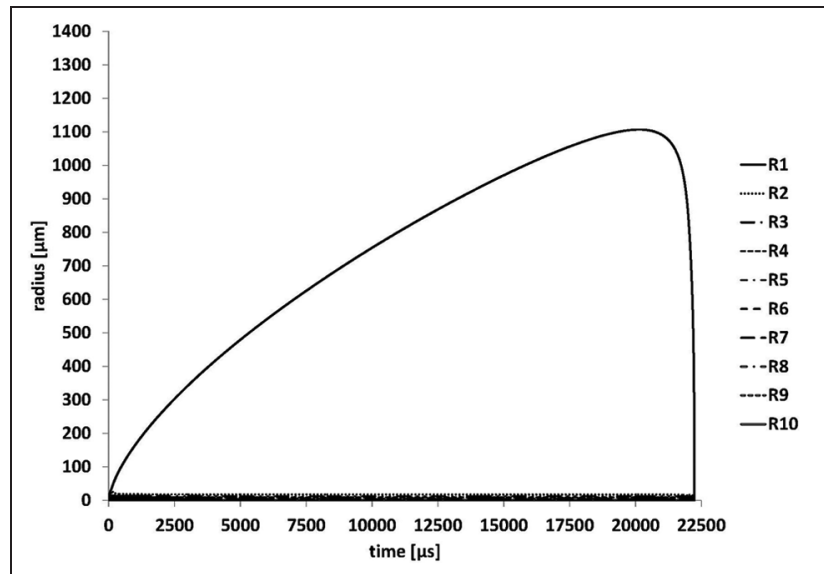

(a)

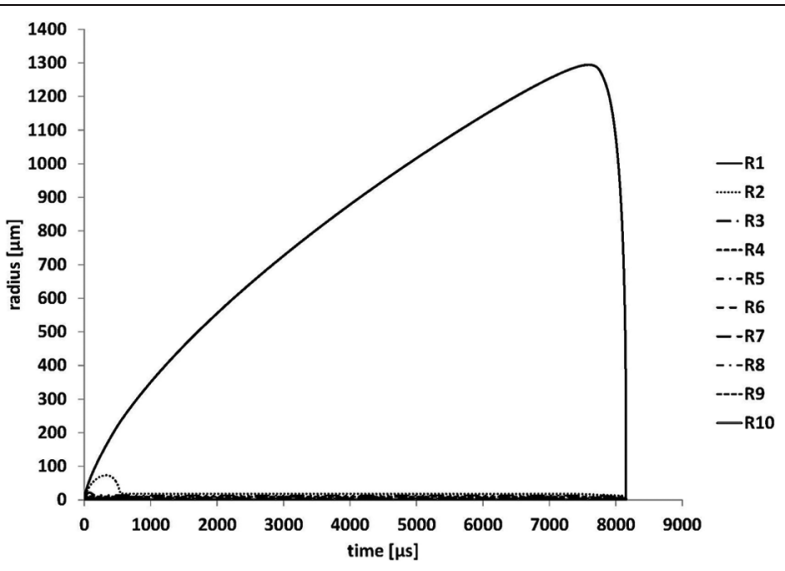

(b)

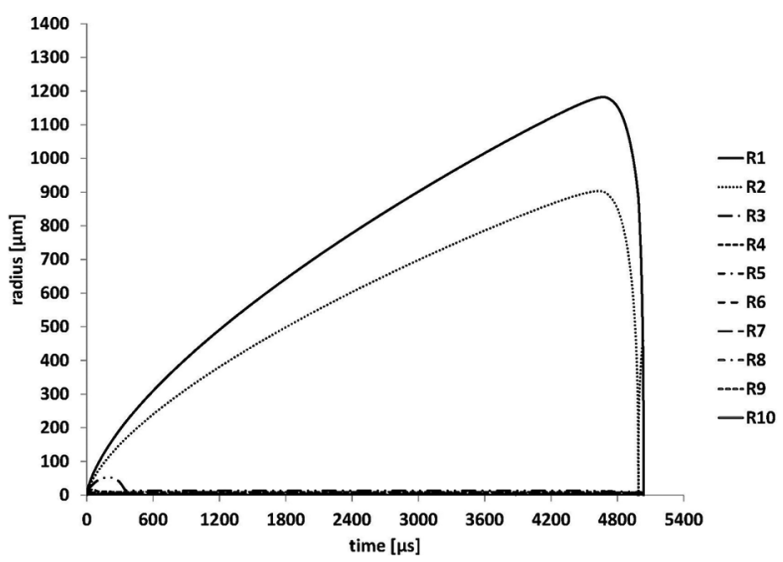

(c)

Figure 17. Time evolution of the radii for (a) $X_{\text {ove }}=1 \mathrm{~mm}, H_{\text {gap }}=12 \mu \mathrm{m}, p_{\text {pump }}=10 \mathrm{bar}$, and $\Omega=50 \mathrm{r} / \mathrm{min}$; (b) $X_{\text {ove }}=1 \mathrm{~mm}, H_{\text {gap }}=12$ $\mu \mathrm{m}, p_{\text {pump }}=10 \mathrm{bar}$, and $\Omega=150 \mathrm{r} / \mathrm{min}$; and (c) $X_{\text {ove }}=1 \mathrm{~mm}, H_{\text {gap }}=12 \mu \mathrm{m}, p_{\text {pump }}=10 \mathrm{bar}$, and $\Omega=250 \mathrm{r} / \mathrm{min}$.

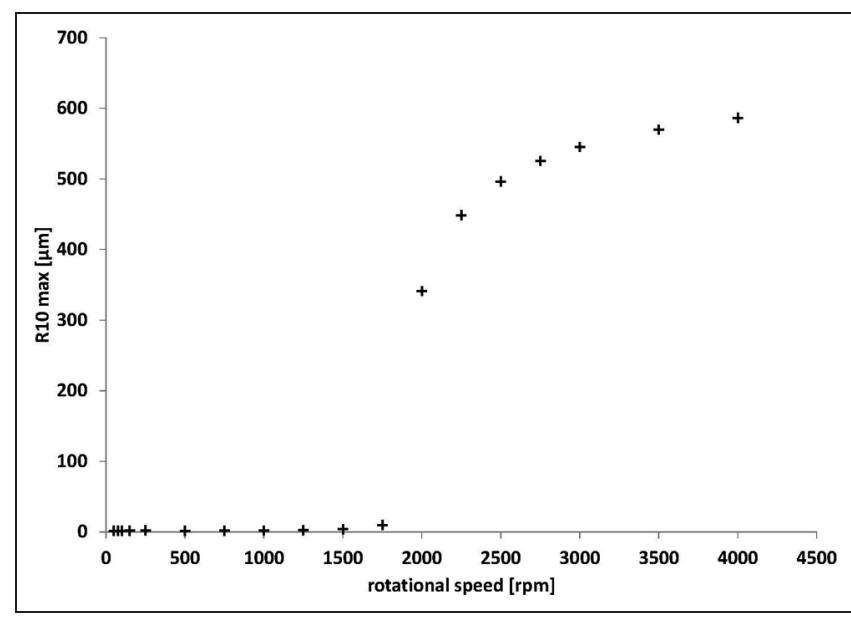

Figure 18. Maximum radius $R_{10}$ with respect to the $\Omega$ for $X_{\text {ove }}=1 \mathrm{~mm}, H_{\text {gap }}=12 \mu \mathrm{m}$, and $p_{\text {pump }}=10 \mathrm{bar}$.

Figure 22 shows that the non-dimensional cavitation duration, the maximum radius of the biggest and smallest bubbles, and the maximum void fraction decrease linearly when the pump outlet pressure is increased, which is consistent with the slight variation of the minimum pressure observed in Figure 21. The void fraction is almost reduced $50 \%$ if the delivery pressure is increased from 5 bar up to 300 bar. This is mainly due to a decrease in all bubble volumes, while all bubbles continue to develop. This result suggests that a booster pump cannot entirely eliminate the cavitation in a hydraulic system. This conclusion should be mitigated since all pressure losses outside the distributor have been neglected here. In reality, if the pressure elevation of the pump is increased, the higher flow rate results in non-negligible losses in all the system, including in the part located downstream the distributor. Consequently, the pressure in the chamber is significantly overestimated in the present approach for such operation conditions.

\section{Conclusion}

In this study, the multibubble model based on the modified Rayleigh-Plesset equation is applied to an oil hydraulic system composed of an oil tank, a boost pump, a rotary distributor, and a piston. Attention was focused on the rotary distributor where the influence of the overlap length, the gap, the rotational speed, and 


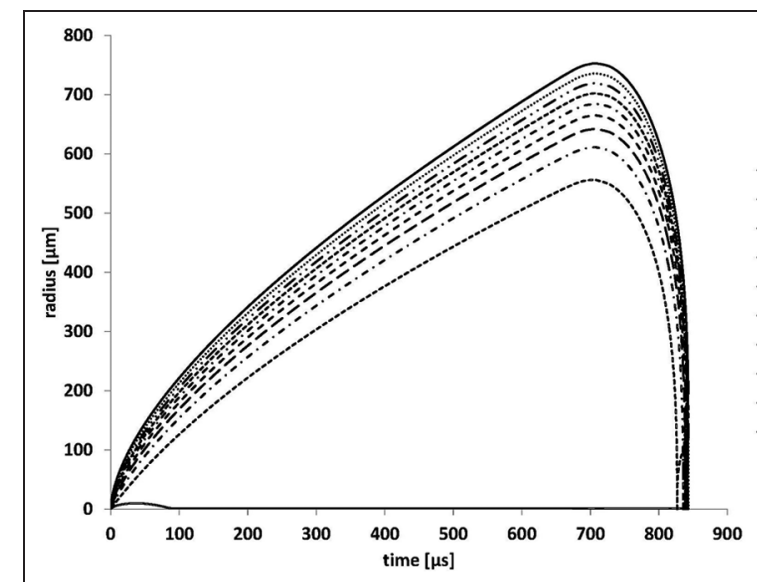

(a)

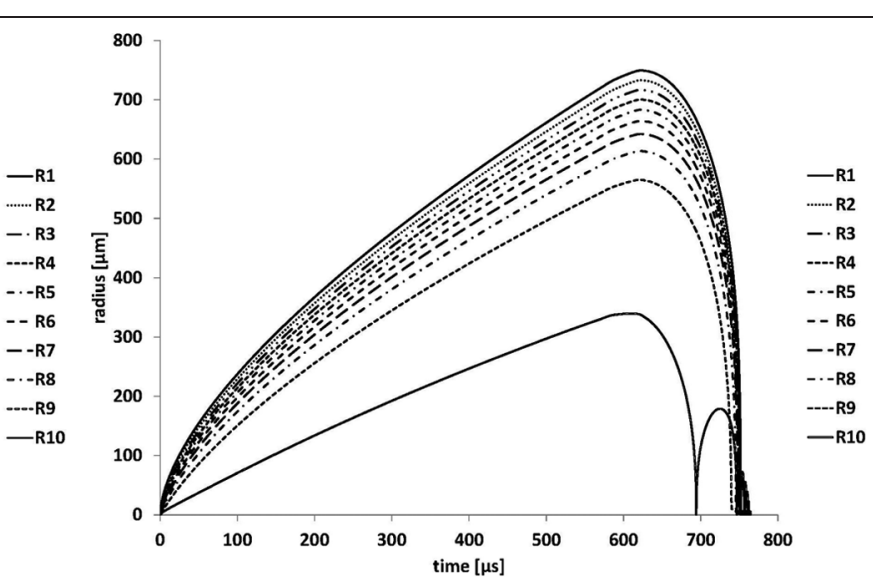

(b)

Figure 19. Time evolution of the bubble radii for (a) $X_{\text {ove }}=1 \mathrm{~mm}, H_{\text {gap }}=12 \mu \mathrm{m}, p_{\text {pump }}=10$ bar, and $\Omega=1750 \mathrm{r} / \mathrm{min}$; (b) $X_{\text {ove }}=1 \mathrm{~mm}$, $H_{\text {gap }}=12 \mu \mathrm{m}, p_{\text {pump }}=10$ bar, and $\Omega=2000 \mathrm{r} / \mathrm{min}$.

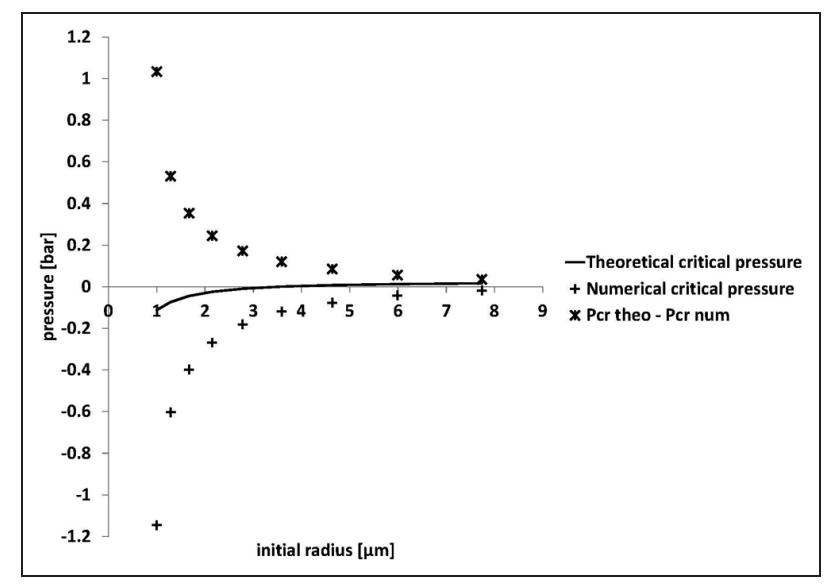

Figure 20. Theoretical critical pressure, numerical critical pressure, and difference between them with respect to the initial radius for $X_{\text {ove }}=I \mathrm{~mm}, H_{\text {gap }}=12 \mu \mathrm{m}$, and $p_{\text {pump }}=10$ bar.

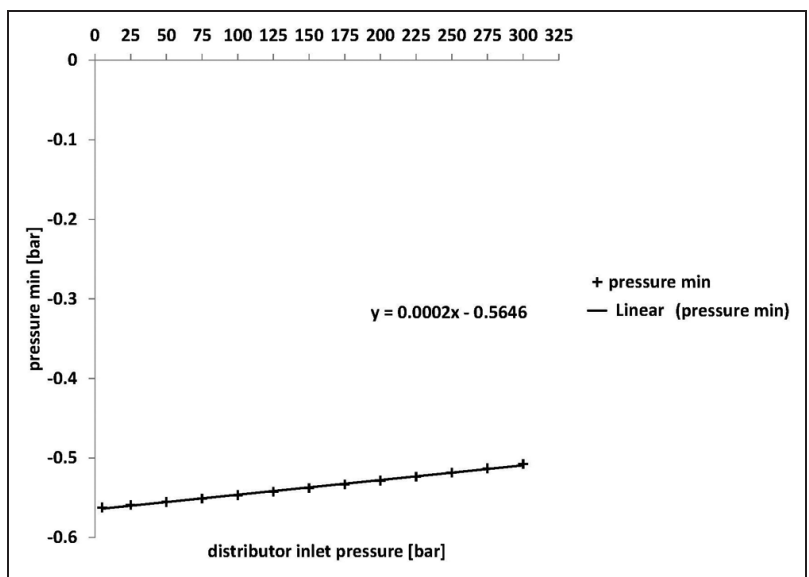

Figure 21. Minimum pressure in the chamber with respect to the distributor inlet pressure for $X_{\text {ove }}=1 \mathrm{~mm}, H_{\text {gap }}=12 \mu \mathrm{m}$, and $\Omega=900 \mathrm{r} / \mathrm{min}$.

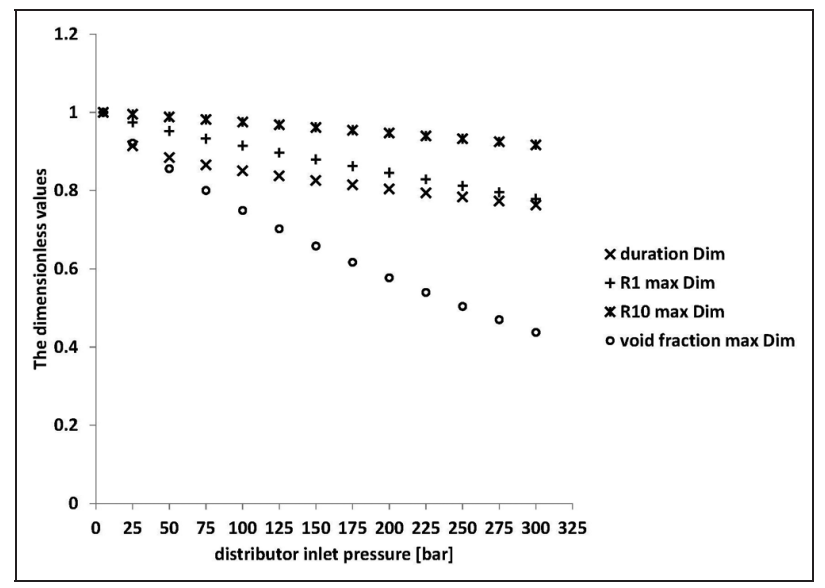

Figure 22. Dimensionless values of the cavitation duration, maximum radius $R_{1}$, maximum radius $R_{10}$, and maximum void fraction with respect to the distributor inlet pressure for $X_{\text {ove }}=1 \mathrm{~mm}, H_{\text {gap }}=12 \mu \mathrm{m}$, and $\Omega=900 \mathrm{r} / \mathrm{min}$ (reference values equal to II $44.912 \mu \mathrm{s}, 787.98 \mu \mathrm{m}, 2.6548 \mu \mathrm{m}$, and 0.0382 , respectively).

the inlet pressure on cavitation inception and the interaction between bubbles was studied.

It was shown that the cavitation duration depends linearly on the overlap length, which has to be minimized. A critical length, which appears to be the limit between a slow increase in the void fraction (for smaller lengths) and a linear rapid increase (for higher values of the length) was obtained. Conversely, the gap does not significantly influence the cavitation phenomenon, for values within a typical range. The study has also shown that a booster pump may not entirely eliminate the cavitation in a hydraulic system. For a distributor inlet pressure increased from 5 up to 300 bar, only a small decrease in the cavitation duration and the size of the bubbles is obtained.

These results confirm that the early stages of distributor opening may generate significant cavitation and 
possible damage and noise emission. Such cavitation may be significantly affected by the detail of the distributor geometry, so taking into account this issue in the process of conception of the system seems necessary to avoid spurious cavitation development and related detrimental effects.

The study has also provided original conclusions regarding the interactions between bubbles, with respect to the multibubble model: when the rotational speed is sufficiently increased, the minimum pressure in the chamber is dropped below the critical pressure of the smallest considered bubble, so all bubbles should theoretically grow. However, the study shows that the growth of the bubbles strongly depends on the interactions with the nearby bigger ones and some of the small bubbles eventually collapse at the early stage of cavitation inception even if the ambient pressure is lower than their theoretical critical one. If the rotational speed is still increased, the initial pressure drop enables these bubbles to gain a sufficient inertia to overcome the interaction phenomena and eventually to develop.

It was shown that the difference between this numerical critical pressure and the theoretical one is especially high for small bubbles, which suggests that the definition of the critical pressure should include the interaction phenomena between bubbles.

As already concluded by $\mathrm{Ohl},{ }^{1}$ the results also confirm that these interaction phenomena are maximum at the early stage of cavitation inception. Only the bubbles that do not collapse at this step will further continue to develop. Conversely, the growth of the small bubbles enhances the interactions with the other bubbles and consequently slows down the growth of the nearby bigger ones.

\section{Declaration of conflicting interests}

The authors declare that there is no conflict of interest.

\section{Funding}

This research received no specific grant from any funding agency in the public, commercial, or not-for-profit sectors.

\section{References}

1. Ohl CD. Cavitation inception following shock wave passage. Phys Fluids 2002; 14(10): 3512-3521.

2. Barre S, Rolland J, Boitel G, et al. Experiments and modeling of cavitating flows in venturi: attached sheet cavitation. Eur J Mech B: Fluid 2009; 28(3): 444-464.

3. Singer BG and Harvey SJ. Cavitation damage studies using plasticine. Int J Mech Sci 1979; 21(7): 409-416.

4. Arndt R, Voigt RJr, Sinclair J, et al. Cavitation erosion in hydroturbines. J Hydraul Eng: ASCE 1989; 115(10): 1297-1315

5. Fortes-Patella R, Reboud J-L and Archer A. Cavitation damage measurement by $3 \mathrm{D}$ laser profilometry. Wear 2000; 246: 59-67.
6. Wang G, Senocak I, Shyy W, et al. Dynamics of attached turbulent cavitating flows. Prog Aerosp Sci 2001; 37: 551-581.

7. Buogo S and Cannelli GB. Implosion of an underwater spark-generated bubble and acoustic energy evaluation using the Rayleigh model. J Acoust Soc Am 2002; 111(6): 2594-2599.

8. Dular M, Bachert R, Stoffel B, et al. Experimental evaluation of numerical simulation of cavitating flow around hydrofoil. Eur J Mech B: Fluid 2005; 24(4): 522 538.

9. Singh S, Choi J-K and Chahine GL. Characterization of cavitation fields from measured pressure signals of cavitating jets and ultrasonic horns. J Fluid Eng: T ASME 2013; 135(9): 091302.

10. Frizell K, Renna F and Matos J. Cavitation potential of flow on stepped spillways. J Hydraul Eng: ASCE 2013; 139(6): 630-636.

11. Talha A, Barrand JP, Neyrat S, et al. étude expérimentale de réduction du bruit d'une pompe à engrenages de borä te de vitesses automatique. Méc Ind 2001; 2(2): 149-156.

12. Ruchonnet N, Alligné S, Nicolet $\mathrm{C}$, et al. Cavitation influence on hydroacoustic resonance in pipe. $J$ Fluid Struct 2012; 28: 180-193.

13. Wang S. The analysis of cavitation problems in the axial piston pump. J Fluid Eng: T ASME 2010; 132(7): 074502 .

14. Chahine GL. Pressures generated by a bubble cloud collapse. Chem Eng Commun 1984; 28: 355-367.

15. Kubota A, Kato $\mathrm{H}$ and Yamaguchi $\mathrm{H}$. A new modelling of cavitating flows: a numerical study of unsteady cavitation on a hydrofoil section. J Fluid Mech 1992; 240: 59-96.

16. Adama Maiga M, Coutier-Delgosha $\mathrm{O}$ and Buisine D. Interactions by exchange of volume between two spherical bubbles. Int J Appl Mech 2014; 6(6): 1450071.

17. Grogger HA and Alajbegovic A. Calculation of the cavitating flow in venturi geometries using two fluid model. In: Proceedings of ASME fluid engineering summer conference, Washington, DC, 21-25 June 1998. FEDSM 98-5295.

18. Owis FM and Nayfeh AH. Numerical simulation of 3-D incompressible, multi-phase flows over cavitating projectiles. Eur J Mech B: Fluid 2004; 23(2): 339-351.

19. Martynov SB, Mason DJ and Heikal MR. Numerical simulation of cavitation flows based on their hydrodynamic similarity. Int J Engine Res 2006; 1(3): 283-296.

20. Coutier-Delgosha O, Stutz B, Vabre A, et al. Analysis of cavitating flow structure by experimental and numerical investigations. J Fluid Mech 2007; 578: 171-222.

21. Goncalvès E. Numerical study of unsteady turbulent cavitating flows. Eur J Mech B: Fluid 2011; 30(1): 26-40.

22. Benaouicha $\mathrm{M}$ and Astolfi J-A. Analysis of added mass in cavitating flow. J Fluid Struct 2012; 31: 30-48.

23. Plesset MS. Dynamics of cavitation bubbles. J Appl Mech 1948; 16: 228-231.

24. Keller JB and Miksis M. Bubble oscillations of large amplitude. J Acoust Soc Am 1980; 68(2): 628-633.

25. Takahira H, Akamatsu T and Fujikawa S. Dynamics of a cluster of bubbles in a liquid. JSME Int $J$ B: Fluid $T$ 1994; 37: 297-305.

26. Ida M, Naoe T and Futakawa M. Suppression of cavitation inception by gas bubble injection: a numerical study 
focusing on bubble-bubble interaction. Phys Rev E 2007; 76: 046309.

27. Bremond N, Arora M, Dammer SM, et al. Interaction of cavitation bubbles on a well. Phys Fluids 2006; 18: 1215505 .

28. Ida M. Multibubble cavitation inception. Phys Fluids 2009; 21: 113302 .

29. Oguz HN and Prosperetti A. A generalization of the impulse and virial theorems with an application to bubble oscillations. J Fluid Mech 1990; 218: 143-162.

30. Doinikov AA. Translational motion of two interacting bubbles in a strong acoustic field. Phys Rev E 2001; 64: 026301.

31. Franc J-P, Kueny J-L, Karimi A, Fruman D-H, Fréchou D, Briançon-Marjollet L, Billard J-Y, Belahadji B, Avellan $\mathrm{F}$ and Michel J-M. La cavitation: Mécanismes physiques et aspects industriels. EDP Sciences-Collection, Grenoble Sciences, p.55, 1995.

32. Lush PA and Peters PI. Visualization of the cavitating flow in a venturi-type duct using high speed cine photography. In: Proceedings of the IAHR conference on operating problems of pump stations an power plants, Amsterdam, 13-18 September 1982, vol. 1, issue 5, pp. 1-13.

33. Hofmann M, Lohrberg H, Ludwig G, Stoffel B, Reboud J-L, Fortes-Patella R. Numerical and experimental investigations on the self-oscillating behaviour of cloud cavitation: part 1 Visualisation/part 2 dynamic pressures. In: Proceedings of the third ASME/JSME joint fluids engineering conference, San Francisco, CA, 18-23 July 1999.

\section{Appendix I}

\section{Notation}

$D_{i j}$

$D_{0}$

$H_{\text {gap }}$

$H_{h e i}$

$i$

j

$L_{\text {dis }}$

$N_{b}$ $p_{e x}(t)$ $p_{c s_{i}}$

$p_{i}$

$p_{g_{i}}$

$p_{c}$

$p_{\text {pump }}$

$p_{v}$

$p_{0}$

$q_{i}=4 \pi R_{i}^{2} \dot{R}_{i}$

$\dot{q}_{i}=\frac{\partial q_{i}}{\partial t}=$

$4 \pi\left(2 R_{i} \dot{R}_{i}^{2}+R_{i}^{2} \ddot{R}_{i}\right)$

$Q_{\text {dis }}$

$Q_{\text {pis }}$

$R_{c s_{i}}$

$R_{\text {cra }}$

$R_{\text {dis }}$

$R_{i}$

$R_{0 i}$

$\dot{R}_{i}$

$\ddot{R}_{i}$

$S_{\text {pis }}$

$t$

$V_{c h}$

$X_{\text {clo }}$

$X_{\text {dis }}$

$X_{\text {ope }}$

$X_{\text {ove }}$

$\gamma$

$\delta p_{c l o}$

distance between the centers of

bubble $i$ and bubble $j(\mathrm{~m})$

constant that links $D_{i j}$ and the

initial radii of bubble $i$ and

bubble $j(-)$

gap length $(\mathrm{m})$

chamber height $(\mathrm{m})$

index $i$ corresponds to the bubble

$i(-)$

index $j$ corresponds to the bubble

$j(-)$

distributor length in the $z$

direction $(\mathrm{m})$

$\omega$

number of bubbles $(-)$

ambient pressure $(\mathrm{Pa})$ critical pressure $(\mathrm{Pa})$

pressure in the liquid at the

bubble interface $(\mathrm{Pa})$

gas pressure $(\mathrm{Pa})$

chamber pressure $(\mathrm{Pa})$

pressure at the pump outlet $(\mathrm{Pa})$

vapor pressure $(\mathrm{Pa})$

atmospheric pressure $(\mathrm{Pa})$

bubble $i$ flow rate $\left(\mathrm{m}^{3} / \mathrm{s}\right)$

time derivative of flow rate

$\left(\mathrm{m}^{3} / \mathrm{s}^{2}\right)$

distributor flow rate $\left(\mathrm{m}^{3} / \mathrm{s}\right)$

piston flow rate $\left(\mathrm{m}^{3} / \mathrm{s}\right)$

bubble $i$ critical radius (m)

crank shaft radius $(\mathrm{m})$

radius of the distributor $(\mathrm{m})$

bubble $i$ radius (m)

initial bubble $i$ radius (m)

velocity normal to the bubble $i$

interface $(\mathrm{m} / \mathrm{s})$

interface acceleration $\left(\mathrm{m} / \mathrm{s}^{2}\right)$

piston section $\left(\mathrm{m}^{2}\right)$

time (s)

chamber volume $\left(\mathrm{m}^{3}\right)$

distributor travel for $X_{d i s}<0$ (m)

abscissa of $M(\mathrm{~m})$

distributor travel for $X_{d i s}>0(\mathrm{~m})$

overlap length (m)

polytropic exponent (-)

pressure drop if the distributor is closed $(\mathrm{Pa})$

pressure drop if the distributor is opened $(\mathrm{Pa})$

pressure drop $(\mathrm{Pa})$

time step (s)

dynamic viscosity of the liquid

(Pa s)

density of the liquid $\left(\mathrm{kg} / \mathrm{m}^{3}\right)$

surface tension $(\mathrm{N} / \mathrm{m})$

the angular position of the

distributor (where $O$ is located at

the distributor is axis and $M$ is at

its periphery) (rad)

angular velocity $(\mathrm{rad} / \mathrm{s})$

rotational speed (r/min) 